\title{
Extratropical cyclones and the projected decline of winter Mediterranean precipitation in the CMIP5 models
}

\author{
Giuseppe Zappa $\cdot$ Matthew K. Hawcroft • \\ Len Shaffrey $\cdot$ Emily Black $\cdot$ David J. Brayshaw
}

Received: 23 July 2014 / Accepted: 21 November 2014 / Published online: 2 December 2014

(c) The Author(s) 2014. This article is published with open access at Springerlink.com

\begin{abstract}
The Mediterranean region has been identified as a climate change "hot-spot" due to a projected reduction in precipitation and fresh water availability which has potentially large socio-economic impacts. To increase confidence in these projections, it is important to physically understand how this precipitation reduction occurs. This study quantifies the impact on winter Mediterranean precipitation due to changes in extratropical cyclones in 17 CMIP5 climate models. In each model, the extratropical cyclones are objectively tracked and a simple approach is applied to identify the precipitation associated to each cyclone. This allows us to decompose the Mediterranean precipitation reduction into a contribution due to changes in the number of cyclones and a contribution due to changes in the amount of precipitation generated by each cyclone. The results show that the projected Mediterranean precipitation reduction in winter is strongly related to a decrease in the number of Mediterranean cyclones. However, the contribution from changes in the amount of precipitation generated by each cyclone are also locally important: in the East Mediterranean they amplify the precipitation trend due to the reduction in the number of cyclones, while in the North Mediterranean they compensate for it. Some of the processes that determine the opposing cyclone precipitation intensity responses in the North and East Mediterranean regions are investigated by exploring the CMIP5 intermodel spread.
\end{abstract}

G. Zappa $(\bowtie) \cdot$ L. Shaffrey $\cdot$ E. Black $\cdot$ D. J. Brayshaw

NCAS-Climate and Department of Meteorology,

University of Reading, Reading, UK

e-mail: g.zappa@ reading.ac.uk

M. K. Hawcroft

Department of Meteorology, University of Reading, Reading, UK
Keywords Mediterranean climate $\cdot$ Precipitation projections $\cdot$ Extratropical cyclones $\cdot$ CMIP5

\section{Introduction}

The Mediterranean area has been identified as a climate change "hot-spot" (Giorgi 2006; Diffenbaugh and Giorgi 2012). Under climate change scenarios, the precipitation in the Mediterranean region is projected to decline leading to increasing aridification and reduction in fresh water supplies (Mariotti et al. 2008; Jin et al. 2010; Collins et al. 2013; Seager et al. 2014). This may have serious socioeconomic impacts in regions such as the Middle East and Northern Africa which are already affected by water scarcity (Arnell 2004). To increase confidence in these future projections it is important to understand the physical processes controlling the Mediterranean hydro-climate and how they will respond to climate change.

The development of synoptic scale extratropical cyclones in the Mediterranean region (Mediterranean cyclones) is a key atmospheric process of the Mediterranean climate. For example, Trigo et al. (2000) found that the number of Mediterranean cyclones and the amount of Mediterranean precipitation are associated in the interannual variability. Mediterranean cyclones are typically generated by lee cyclogenesis (Speranza et al. 1985; Buzzi et al. 1990) following from the interaction of weather systems propagating across Western or Central Europe with the orography of the Mediterranean region. In winter, which is the most active season, intense cyclogenetic areas are found in the Gulf of Genoa, in the Aegean Sea and in the Black Sea (Trigo et al. 2002) and a regional Mediterranean storm track has been identified in the meteorological reanalyses (Hoskins and Hodges 2002). A smaller 
fraction of Mediterranean cyclones [about $10 \%$ according to Romem et al. (2007)] are generated outside of the Mediterranean region and propagate into it from either North Africa or the North Atlantic ocean.

Given the important role of extratropical cyclones and their associated fronts in generating precipitation in the extratropics (Catto et al. 2012; Hawcroft et al. 2012), future changes in the mean precipitation at a given location might be affected by both changes in the local number of extratropical cyclones and by changes in the amount of precipitation generated by each cyclone (Finnis et al. 2007). A number of studies have identified a future reduction in the number of Mediterranean cyclones under climate change scenarios (Schubert et al. 1998; Lionello et al. 2002; Geng and Sugi 2003; Bengtsson et al. 2006; Lionello and Giorgi 2007; Pinto et al. 2007; Raible et al. 2010; Black et al. 2010; Nissen et al. 2013; Zappa et al. 2013b). By the end of the 21 st century, under the RCP4.5 emission scenario, a robust reduction of 10-20\% in the number of Mediterranean cyclones in winter has been also found by Zappa et al. (2013b) in the climate models participating in the fifth phase of the Coupled Model Intercomparison Project (CMIP5). The reduction in the number of Mediterranean cyclones has been suggested to be a main contributor to the projected decline in precipitation in the South and East Mediterranean regions in winter (Lionello and Giorgi 2007), although their impact has not been quantified. Furthermore, Trigo et al. (2000) suggested that the negative precipitation trend in the North Mediterranean area between 1958 and 1996 was also linked to a reduction in the number of strong Mediterranean cyclones.

While the response in the number of Mediterranean cyclones has been intensively investigated, less attention has been given so far to understanding how the amount of precipitation generated by individual Mediterranean cyclones will change in the future. However, studies focused on the main oceanic storm tracks have suggested that the precipitation intensity of the extratropical cyclones is expected to increase under climate change (Bengtsson et al. 2006; Watterson 2006; Finnis et al. 2007; Zappa et al. 2013b). Moreover, Finnis et al. (2007) showed that this increase in the precipitation intensity of extratropical cyclones is responsible for the projected increase in the mid and high latitude annual mean precipitation in a climate model, while the changes in the number of extratropical cyclones tended to be of smaller importance. This increase in the mean amount of precipitation generated by cyclones is explained by an increase in the atmospheric moisture content and evaporation which leads to an higher moisture convergence toward the extratropical cyclones and moisture uplift in the associated fronts (Trenberth 2011).

These results suggest that future trends in Mediterranean precipitation might be affected by two opposing processes, as the number of cyclones is projected to decrease while the precipitation generated by each cyclone might be expected to increase. This leads to some open questions: why is the Mediterranean precipitation projected to decline, and are the two processes both important for interpreting the future changes in Mediterranean precipitation? This study seeks to answer these questions by quantifying the contribution to the winter (DJF) precipitation projections from changes in the number of Mediterranean cyclones and the contribution from changes in the precipitation intensity of cyclones. The choice of the season is motivated by the high activity of synoptic cyclones in DJF. The precipitation responses to climate change from 17 CMIP5 climate models are analysed so that robust responses can be identified and the sources of uncertainty in the future projections discussed.

The structure of the paper is as follows. Section 2 describes the data and methods. Section 3 discusses the ability of CMIP5 models to represent the observed spatial distribution of Mediterranean cyclones. Section 4 presents the climatology of the precipitation associated with extratropical cyclones in the CMIP5 models and its response to climate change. In Sect. 5, the cyclone-associated precipitation response is decomposed between the contribution due to changes in the number and in the precipitation intensity of cyclones, and an interpretation of the precipitation intensity response is presented in Sect. 6. Conclusions are given in Sect. 7.

\section{Data and methods}

\subsection{CMIP5 models}

17 CMIP5 coupled climate models are considered in this study (see Table 1). The climate change response is evaluated as the difference between an 18 year period at the end of the twenty-first century (2082-2099) under the RCP8.5 emission scenario and a 30 year period (1976-2005) in the historical simulations. The shorter time period in the RCP8.5 scenario compared to the historical period is due to limited data availability. Six hourly average precipitation rate, which is needed for attributing precipitation to extratropical cyclones (see Sect. 2.3), is only available in the CMIP5 end-of-century standard output for 2082-2099. For simplicity, one ensemble member is considered for each model and simulation. Using multiple ensemble members for each model is unlikely to substantially affect the conclusions and this has been tested for some models that have the needed data available for multiple members.

The ability of CMIP5 models to represent the Mediterranean hydrological cycle has been analysed in detail by Kelley et al. (2012) and Seager et al. (2014). These studies show that the CMIP5 models, on average, have a 
Table 1 List of analysed CMIP5 models including the horizontal and vertical resolution of the atmospheric component of the model
The last column gives the DJF root mean square track density bias (units of cyclones/month) in the Mediterranean region $\left(30^{\circ} \mathrm{N}-45^{\circ} \mathrm{N}\right.$ and $\left.10^{\circ} \mathrm{W}-40^{\circ} \mathrm{E}\right)$ compared to the ERA-Interim reanalysis

\begin{tabular}{|c|c|c|c|c|c|}
\hline \multirow[t]{2}{*}{ No. } & \multicolumn{2}{|l|}{ Basic information } & \multicolumn{2}{|l|}{ Atm. resolution } & \multirow{2}{*}{$\begin{array}{l}\text { Track density } \\
\text { RMS bias }\end{array}$} \\
\hline & Model name & Institution & Horizontal & $\overline{\text { Vertical }}$ & \\
\hline 1 & BCC-CSM1-1 & BCC, China & $\mathrm{T} 42(128 \times 64)$ & 26 & 4.17 \\
\hline 2 & BCC-CSM1-1m & & $\mathrm{T} 106(320 \times 160)$ & 26 & 3.00 \\
\hline 3 & CCSM4 & NCAR, USA & $280 \times 200$ & 27 & 2.68 \\
\hline 4 & CMCC-CM & CMCC, Italy & $\mathrm{T} 159$ & 31 & 1.68 \\
\hline 5 & EC-EARTH & European Consortium, Europe & TL159 $(320 \times 160)$ & 62 & 0.73 \\
\hline 6 & FGOALS-g2 & LASG, China & $128 \times 60$ & 26 & 5.79 \\
\hline 7 & GFDL-ESM2M & GFDL, USA & $144 \times 90$ & 24 & 3.07 \\
\hline 8 & GFDL-ESM2G & & $144 \times 90$ & 24 & 2.85 \\
\hline 9 & GFDL-CM3 & & C48 $(144 \times 90)$ & 48 & 1.90 \\
\hline 10 & INMCM4 & INM, Russia & $180 \times 120$ & 21 & 3.57 \\
\hline 11 & IPSL-CM5A-LR & IPSL, France & $96 \times 96$ & 39 & 2.16 \\
\hline 12 & IPSL-CM5A-MR & & $144 \times 143$ & 39 & 2.03 \\
\hline 13 & MIROC5 & MIROC, Japan & T63 $(192 \times 96)$ & 56 & 1.97 \\
\hline 14 & MIROC-ESM & & $\mathrm{T} 42(128 \times 64)$ & 80 & 4.09 \\
\hline 15 & MIROC-ESM-CHEM & & $\mathrm{T} 42(128 \times 64)$ & 80 & 3.82 \\
\hline 16 & MRI-CGCM3 & MRI, Japan & TL159 $(320 \times 160)$ & 48 & 2.08 \\
\hline 17 & NorESM1-M & NCC, Norway & $144 \times 96$ & 26 & 3.16 \\
\hline
\end{tabular}

reasonable representation of the observed Mediterranean precipitation, evaporation and moisture fluxes in winter. A brief validation of the representation of the Mediterranean storm track in the CMIP5 models will be given in Sect. 3 .

\subsection{Cyclone tracking}

Extratropical cyclones are identified using the objective cyclone tracking algorithm introduced by Hodges (1995) and which has already been applied to track extratropical cyclones in the CMIP5 climate models (e.g. Zappa et al. 2013a, b). Extratropical cyclones are identified as maxima above $1 \times 10^{-5} \mathrm{~s}^{-1}$ in the 6 hourly vorticity at $850 \mathrm{hPa}$ truncated at T42 resolution. Spectral waves of total wavenumber smaller than 5 are also removed to filter out the large scale planetary waves. Using this approach, synoptic cyclones of similar spatial scales are identified across a set of models covering a range of horizontal resolutions (100$300 \mathrm{~km}$ grid spacing).

The detected vorticity features with lifetime exceeding 2 days and along-track maximum T42 vorticity intensity of at least $3 \times 10^{-5} \mathrm{~s}^{-1}$ are retained for analysis. This slightly differs from the standard setup of the tracking algorithm used in previous studies of the oceanic storm tracks, where a minimum displacement threshold of $1,000 \mathrm{~km}$ but no additional threshold on vorticity intensity are used (e.g. Zappa et al. 2013a). Removing the minimum displacement threshold is motivated by the tendency of Mediterranean cyclones to occasionally show quasi-stationary behaviour (Trigo et al. 1999). The additional threshold on the cyclone maximum vorticity intensity is introduced to filter spurious signals associated with very weak quasi-stationary vorticity features. Depending on the model, 4-16\% of the detected winter Mediterranean cyclones propagate less than $1000 \mathrm{~km}$ in the CMIP5 model historical simulations. However, the conclusions of the paper are insensitive to using the standard setup of the tracking algorithm which does not include quasi-stationary features. This seems consistent with results from Ulbrich et al. (2013) which show that the climate change response in the number of Mediterranean cyclones does not strongly depend on the choice of the cyclone identification and tracking algorithm.

\subsection{Decomposing the precipitation response}

The methodology introduced by Hawcroft et al. (2012) has been adapted here to decompose the precipitation response to climate change between the contribution due to changes in the number of cyclones and the contribution due to changes in the amount of precipitation generated by each cyclone. The approach is similar to that adopted by Finnis et al. (2007) in their study of the mid and high latitude precipitation projections. In the Hawcroft et al. (2012) framework, each cyclone has a fixed radius of influence $(\mathrm{R})$, and all the precipitation falling within the radius of influence from the cyclone centre is assumed to be associated with the cyclone. Similarly, a grid point is defined to be under the influence of cyclones if there is at least one cyclone centre within distance $\mathrm{R}$ from the grid point. The precipitation associated with cyclones is determined using 6 hourly average precipitation rate centred at the time steps of cyclone identification, which is an improvement compared to the daily average precipitation used in Hawcroft et al. (2012). 
A radius of influence $\mathrm{R}$ of $10^{\circ}$ has been found to be appropriate for the Mediterranean cyclones in the CMIP5 models and the choice of this radius is justified in "Appendix". The chosen radius is smaller than the $12^{\circ}$ used in Hawcroft et al. (2012) to capture the precipitation generated by the extratropical cyclones of the oceanic stormtracks. This is consistent with the smaller size characteristic of Mediterranean cyclones (Trigo et al. 1999) and also with the use of a higher temporal frequency which allows to better define the radius of influence. Moreover, sensitivity tests using different radii have been also performed and the conclusions of the paper are found insensitive to this choice (see "Appendix").

Using this framework, the accumulated seasonal precipitation at a grid point $P(x, y)$ can be decomposed as:

$P=P_{c}+r$

where $P_{c}(x, y)$ is the accumulated precipitation forming under the influence of cyclones, i.e. the precipitation falling while a cyclone centre is within distance $\mathrm{R}$ from the grid point $(x, y) . r(x, y)$ is a residual term which can include contributions from isolated orographic or convective precipitation, or also precipitation generated by long trailing fronts that extend further than $\mathrm{R}$ from the cyclone centre.

The accumulated precipitation under the influence of cyclones can be further expressed as:

$P_{c}=N \cdot \mu$,

where $N(x, y)$ is the total number of time steps the grid point $(x, y)$ is under the influence of cyclones and $\mu(x, y)$ is the mean precipitation which falls during these time steps. Therefore, $\mu(x, y)$ gives a local measure of the average precipitation intensity of cyclones at that location.

Finally, by taking the difference $(\delta)$ between a future scenario simulation and a historical simulation, the precipitation response to climate change $\left(\delta P=P^{R C P 85}-P^{20 C}\right)$ is given by the change in the cyclone associated precipitation response plus the change in the residual $\left(\delta P=\delta P_{c}+\delta r\right)$. Moreover, the cyclone associated precipitation response can be decomposed as

$\delta P_{c}=\delta N \cdot \mu^{20 C}+\delta \mu \cdot N^{20 C}+\delta \mu \cdot \delta N$,

where $\delta N \cdot \mu^{20 C}$ is the precipitation response due to changes in the number of cyclones, $\delta \mu \cdot N^{20 C}$ is the contribution due to changes in the precipitation intensity of cyclones, $\delta \mu \cdot \delta N$ is a nonlinear cross-term. In the regions where the cross term $(\delta \mu \cdot \delta N)$ and the response in the residual term $(\delta r)$ are small, then

$\delta P \sim \delta N \cdot \mu^{20 C}+\delta \mu \cdot N^{20 C}$

so that the future precipitation response to climate change is partitioned between the impact from changes in the number and in the precipitation intensity of cyclones.
By definition, all the cyclone tracks passing within $10^{\circ}$ from the Mediterranean area $\left(30^{\circ} \mathrm{N}-45^{\circ} \mathrm{N}, 10^{\circ} \mathrm{W}-40^{\circ} \mathrm{E}\right)$ can influence Mediterranean precipitation. This primarily includes Mediterranean cyclones but also some nearby European and Eastern Atlantic extratropical cyclones. To deal with the range of different model resolutions, the 6 hourly precipitation field of each CMIP5 model has been first interpolated to a $1^{\circ} \times 1^{\circ}$ grid using a conservative remapping method (Jones 1999). For an easier interpretation of the results, all the precipitation related quantities will be presented as fluxes $\left(\mathrm{mm}\right.$ day $\left.^{-1}\right)$ rather than as accumulated values.

\section{How well do CMIP5 models represent the Mediterranean storm track?}

Having a realistic representation of Mediterranean cyclones is important to have confidence in the models projections. Therefore, the ability of CMIP5 models to capture the spatial distribution of Mediterranean cyclones is here explored. For doing this, the Mediterranean cyclone track density in winter in the CMIP5 historical simulations (1976-2005) is compared to that in the European Centre for MediumRange Weather Forecasts (ECMWF) Interim reanalysis (ERA-Interim) for the period 1980-2009 (Dee et al. 2011).

Figure 1a shows that the Mediterranean storm track in the ERA-Interim reanalysis is characterised by a narrow band of high track density that extends between the Gulf of Genova (South-West of the Alps) and the East Mediterranean Sea. The multi-model mean track density in the CMIP5 models also shows a maximum south of the Alps with high values extending eastward (see Fig. 1b). This suggests that the CMIP5 models are successful at generating a Mediterranean storm track, although there are some biases compared to ERA-Interim. On average, the simulated Mediterranean storm track tends to have too low track density values and to be displaced northward over the East Mediterranean region compared to the ERA-Interim reanalysis. Zappa et al. (2014) found that the Mediterranean track density underestimation is associated to the tendency of climate models to underestimated the frequency of atmospheric blocking over Europe.

The inspection of the individual CMIP5 models reveals substantial spread in their ability to represent the Mediterranean storm track. For example, the root mean square (RMS) track density bias of the individual models in the Mediterranean region is presented in Table 1. The RMS bias varies between 0.7 (EC-EARTH) and 5.8 (FGOALSg2) number of cyclones per month per unit area. ${ }^{1}$ The mean track density of the four models with the smallest rms bias (EC-EARTH, CMCC-CM, GFDL-CM3 and MIROC5) is

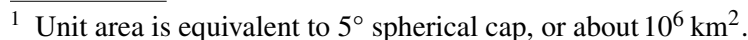



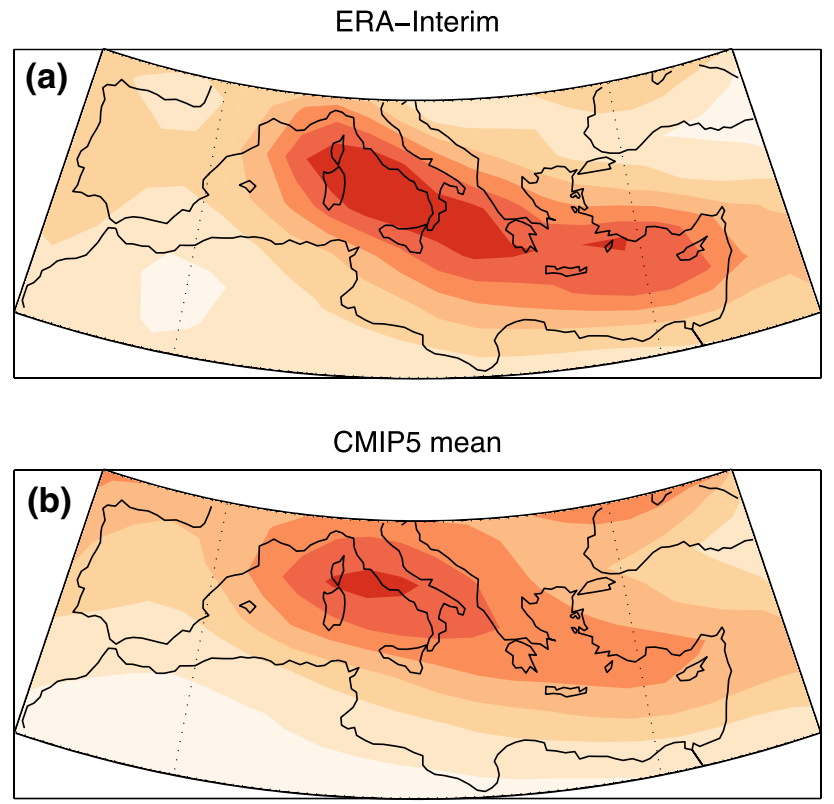

4 CMIP5 models smallest bias mean
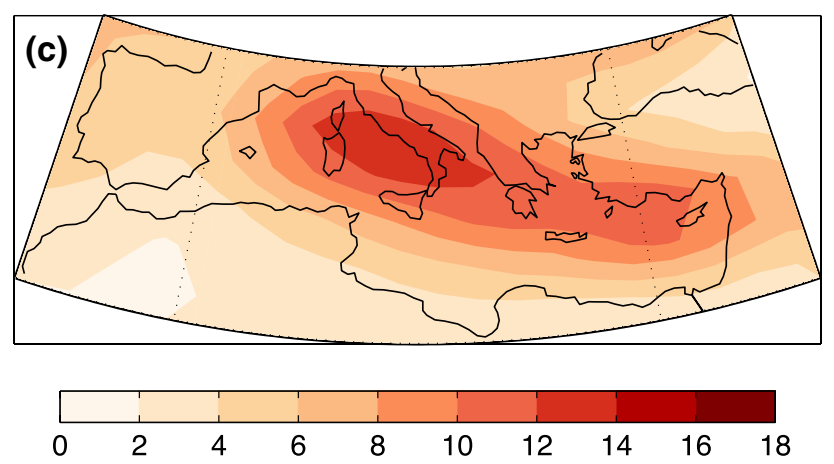

Fig. 1 a DJF track density in the ERA-Interim reanalysis (19792008). b CMIP5 DJF multi-model mean track density in the historical simulations (1976-2005). $\mathbf{c}$ As in b but considering only the 4 CMIP5 models with the smallest root mean square track density bias in the Mediterranean region (see Table 1). Units are in cyclones per month per unit area, where unit area is equivalent to $5^{\circ}$ spherical cap

presented in Fig. 1c. The comparison of Fig. 1a with Fig. 1c suggests that some of the CMIP5 models reproduce the position and eastward extension of the Mediterranean storm track found in the ERA-Interim reanalysis. In addition, the spread in the ability of CMIP5 models to represent the Mediterranean stormtrack track density will allow the sensitivity of the results to the model biases to be discussed (see Sect. 5).

\section{The cyclone associated precipitation}

In this section, the CMIP5 multi-model mean precipitation and the cyclone-associated precipitation will be analysed in both the historical simulations and in the climate change RCP8.5 scenario simulations. Figure $2 \mathrm{a}$ shows the multimodel mean precipitation in the CMIP5 historical simulations in DJF. The highest precipitation rates, which are above $4 \mathrm{~mm} \mathrm{day}^{-1}$, are found in North West Iberia. Precipitation rates of the order of $2 \mathrm{~mm} \mathrm{day}^{-1}$ are found in the North Mediterranean area and values up to $3 \mathrm{~mm} \mathrm{day}^{-1}$ are found close to orographic areas such as the Alps, the Balkans and the Anatolian Peninsula. Precipitation rates of $1 \mathrm{~mm} \mathrm{day}^{-1}$, and rapidly decreasing inland, are found along the Southern and Eastern Mediterranean coast. Consistently with Kelley et al. (2012), we find that the spatial distribution of precipitation of the CMIP5 models resembles that found in the Global Precipitation Climatology Centre (GPCP) dataset, while the total precipitation in the Mediterranean area is on average underestimated of about $0.5 \mathrm{~mm} \mathrm{day}^{-1}$ (not shown).

Under the RCP8.5 scenario, the multi-model mean winter precipitation response shows a reduction over the whole Mediterranean area, and particularly in a zonal band between $35^{\circ} \mathrm{N}$ and $40^{\circ} \mathrm{N}$ (Fig. 2b). Within this band, the largest precipitation reduction (up to $-0.75 \mathrm{~mm} \mathrm{day}^{-1}$ ) is found in the East Mediterranean, i.e. in the areas of Cyprus, Southern Turkey and the East Mediterranean coast. In these regions, the projected change is equivalent to about a $30 \%$ reduction relative to the historical (1976-2005) values. In contrast, there are only small changes (up to about $0.1 \mathrm{~mm} \mathrm{day}{ }^{-1}$ ) in the multi-model mean precipitation response in the North Mediterranean area, such as over the North of Italy, southern France and the Black Sea regions.

Using the framework described in Sect. 2.3, the precipitation associated with cyclones has been identified for each CMIP5 model in both the historical and RCP8.5 simulations. Figure $2 \mathrm{c}$ shows that in the historical simulations the multi-model mean cyclone-associated precipitation resembles the total precipitation field (Fig. 2a) and it reproduces the local maxima associated with the orographic enhancement. Moreover, Fig. 2e shows that the fraction of precipitation associated with extratropical cyclones is greater than $70 \%$ over most of the Mediterranean Sea, and a peak above $75 \%$ is found in the central Mediterranean area. This maximum might be related to the strong influence exerted by Genoa low cyclones in this region. In contrast, the fraction of cyclone associated precipitation over Gibraltar and western Iberia is of the order of $50 \%$, which is likely related to the higher influence of long trailing fronts associated with North Atlantic cyclones. This suggests that our approach has more limited value for analysing climate change in the Gibraltar and western Iberia areas, which will therefore be marginally discussed in this paper. More insight into this region might be obtained using front-identification based approaches, such as that adopted in Catto and Pfahl (2013). 

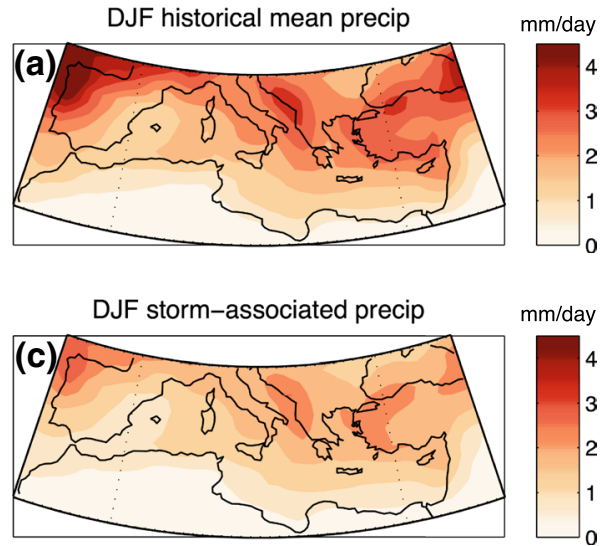

Fraction of storm associated precip
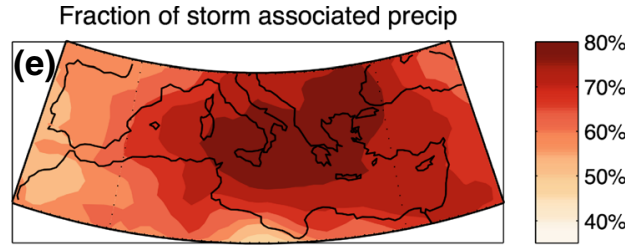

Fig. 2 The left column (a, c, e) refers to the CMIP5 multi-model mean winter (DJF) precipitation in the historical simulations (19762005). a Total precipitation, c precipitation which is identified to be associated with extratropical cyclones and $\mathbf{e}$ fraction of cyclone associated precipitation to the total precipitation. The right column (b, d, f) refer to the CMIP5 multi-model mean DJF precipitation response to climate change computed as the difference between the RCP8.5

The multi-model mean cyclone-associated precipitation response under the RCP8.5 scenario is presented in Fig. 2d. The comparison of Fig. $2 d$ with Fig. $2 b$ shows that the cyclone-associated precipitation response resembles the total precipitation response. In particular, the cyclone-associated precipitation response identifies that the largest precipitation reduction is projected to occur in the East Mediterranean area and that small changes are projected to occur in the North Mediterranean area. The amplitude of the total precipitation response is also reasonably captured, although it tends to be underestimated in Southern Turkey and, particularly, in the Gibraltar area. This underestimation can be quantified by looking at the residual precipitation response presented in Fig. 2f. As the residual response is everywhere smaller than the cyclone associated precipitation response, Eq. 3 can provide valuable information for interpreting a substantial part of the Mediterranean precipitation projections in terms of changes in the number and precipitation intensity of cyclones.

\section{Decomposing the precipitation projections}

Using Eq. 3, the cyclone associated precipitation response (RCP8.5-HIST) of each CMIP5 model is decomposed
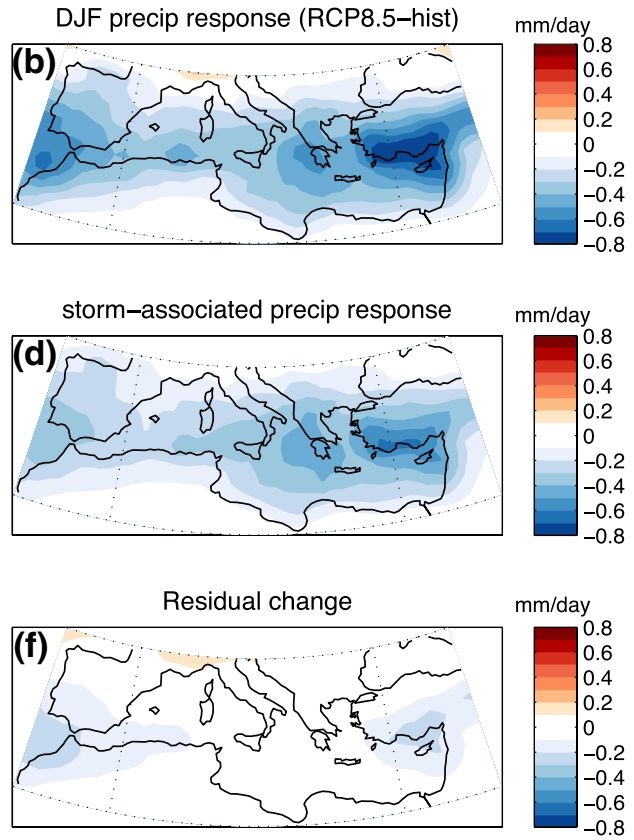

scenario (2082-2099) and the historical simulations. b Total precipitation response, $\mathbf{d}$ response of the precipitation associated with extratropical cyclones and $\mathbf{f}$ response of the precipitation not associated with extratropical cyclones (residual term). Units are in $\mathrm{mm} \mathrm{day}^{-1}$ apart from e which is expressed as \%. The cyclone-associated precipitation is determined as described in Sect. 2.3

between the contribution due to changes in the number of cyclones $\left(\delta N \cdot \mu^{20 C}\right)$, the contribution due to changes in the precipitation intensity of cyclones $\left(\delta \mu \cdot N^{20 C}\right)$ and the contribution due to the cross term $(\delta \mu \cdot \delta N)$. The multi-model mean of the first two terms is presented in Fig. 3a, b, while the cross-term is neglected as it has values everywhere smaller than $0.1 \mathrm{~mm} \mathrm{day}^{-1}$ in both the multi-model mean and in the majority of the individual model responses (not shown).

Figure 3a shows that the impact from future changes in the number of extratropical cyclones in winter is a reduction in the Mediterranean precipitation, particularly in a Northern Mediterranean area extending between Italy and Western Turkey. This is related to the tendency of climate models to show a reduction in the number of Mediterranean cyclones under future climate scenarios (e.g. Ulbrich et al. 2009; Zappa et al. 2013b). This interpretation is confirmed by Fig. 4a which shows the multi-model mean cyclone track density response (RCP8.5-HIST) in the 17 analysed CMIP5 models. The track density is projected to decrease in the whole Mediterranean area and particularly in the Mediterranean storm track region. In the multimodel mean, the total number of Mediterranean cyclones is reduced by about $25 \%$, with all models showing a future reduction in the range -10 to $-40 \%$ (not shown). 

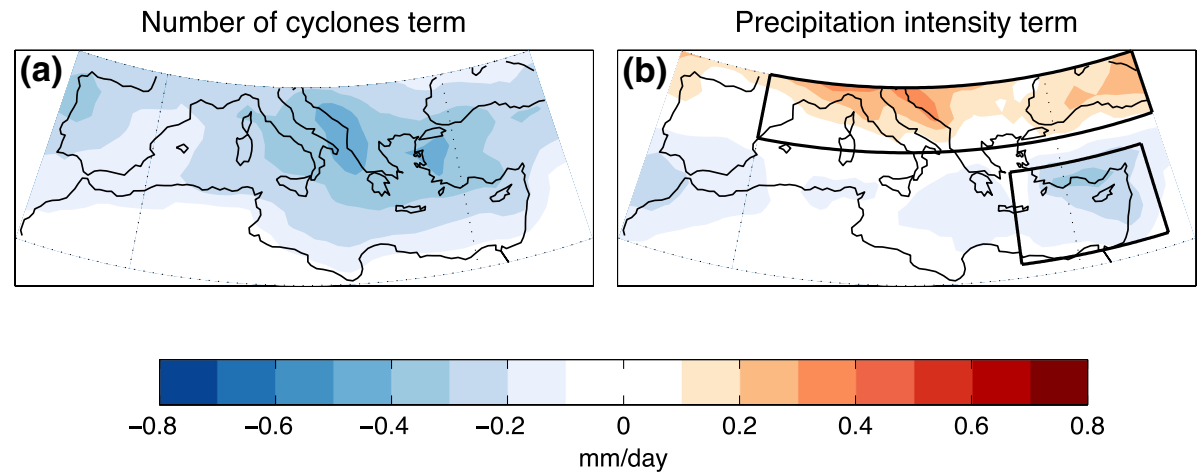

Fig. 3 Decomposition of the DJF precipitation response associated with extratropical cyclones (see Fig. 2d) between the contribution due to changes in the number of cyclones (a) and the contribution due to changes in the average precipitation generated by cyclones $(\mathbf{b})$. These contributions correspond to the first two terms on the right hand side of Eq. 3. The last term of Eq. 3, i.e. the cross-term, has been neglected as it is small compared to the first two terms. The boxes in b delineate the North Mediterranean and East Mediterranean regions where the regional averages for the scatterplots presented in Figs. 5 and 6 are computed. Units are in $\mathrm{mm} \mathrm{day}^{-1}$
A decline in the East Mediterranean precipitation associated with a reduction in the number of Mediterranean cyclones was suggested by Lionello and Giorgi (2007). Although this is consistent with our results, we find that the contribution due to changes in the number of cyclones does not peak in the East Mediterranean in the CMIP5 models. Moreover, we also find that the spatial pattern of the precipitation response due to changes in the number of cyclones differs from the total precipitation response (compare Fig. 3a with Fig 3b). For example, the reduction in the number of cyclones suggests a future reduction in precipitation over North of Italy, while the total precipitation response shows only a small signal there. This suggests that other processes are also important in shaping the Mediterranean precipitation response to climate change.

Figure $3 \mathrm{~b}$ shows that the impact from future changes in the precipitation intensity of cyclones is an increase in the winter precipitation over the North Mediterranean area and a reduction over the East Mediterranean area. This suggests that the small multi-model mean precipitation response over North of Italy results from a compensation between a reduction in the number of Mediterranean cyclones affecting the North of Italy and an increase in the average precipitation generated by each cyclone. On the other hand, the large precipitation reduction which characterises the East Mediterranean results from both a reduction in the number of cyclones and in the precipitation generated by those cyclones.

Possible limitations of these results may arise from the moderate to coarse resolution of the CMIP5 climate models, and from the biases of the models in reproducing the observed position of the Mediterranean storm track. To explore this, we have examined the mean response of the 5 CMIP5 models (EC-EARTH, MRI-CGCM3, CMCC-CM, CCSM4, BCC-CSM1-1m) with finest grid
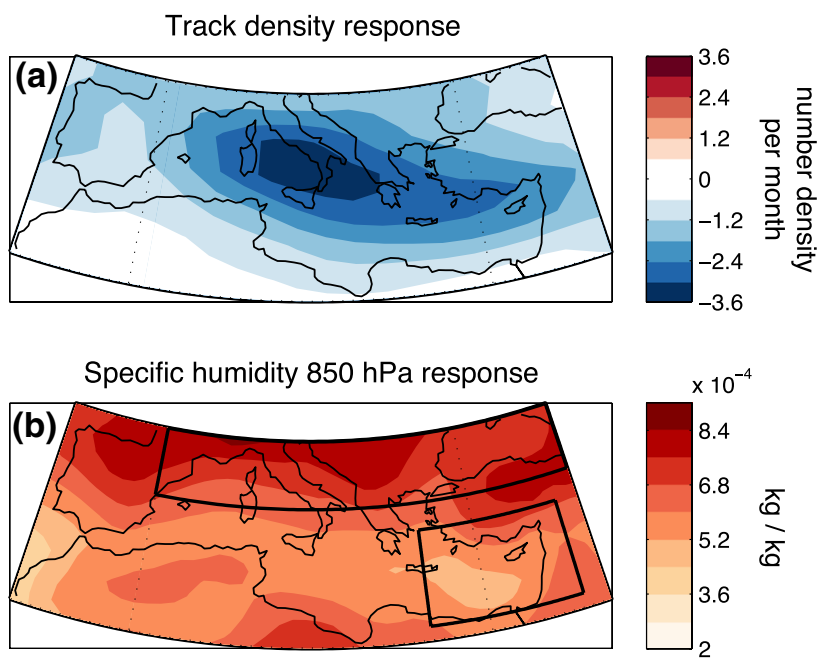

T42 Vorticity intensity response

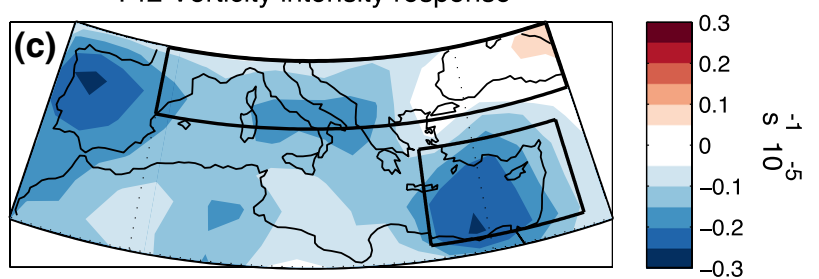

Fig. 4 CMIP5 DJF multi-model mean response under the RCP8.5 scenario in the a cyclone track density, b specific humidity at $850 \mathrm{hPa}$ and $\mathbf{c}$ cyclone T42 vorticity dynamical intensity at $850 \mathrm{hPa}$. Units are a number of cyclones per month per unit area where unit area refers to a $5^{\circ}$ spherical cap, $\mathbf{b ~ k g ~ k g}{ }^{-1}$ and $\mathbf{c} 10^{-5} \mathrm{~s}^{-1}$

spacing (100-150 km) and that from the four models with the smallest track density bias in the Mediterranean region (see Sect. 3). The results (not shown) suggest that the opposite contribution from changes in the precipitation intensity of cyclones between the North and the East Mediterranean 
areas are robust to both model resolution and to the biases in track density within the CMIP5 range.

In summary, the future reduction in the number of Mediterranean cyclones appears to be a key factor controlling the reduction in the overall Mediterranean precipitation. Consistently, we find that the correlation between the area-averaged $\left(0^{\circ} \mathrm{W}-40^{\circ} \mathrm{E}\right.$ and $\left.30^{\circ} \mathrm{N}-45^{\circ} \mathrm{N}\right)$ precipitation response and the track density response across the individual CMIP5 models is +0.85 , so that the models with a larger reduction in the number of Mediterranean cyclones tend to have a larger area-averaged precipitation reduction in the Mediterranean area. However, these results also suggest that understanding the precipitation projections in the Mediterranean sub-regions requires further consideration of the future changes in the amount of precipitation generated by each cyclone. Interestingly, the average amount of precipitation generated by each cyclone decreases in the East Mediterranean, which implies that future changes in the precipitation intensity of cyclones do not simply result from an increase in the atmospheric moisture content. A possible reason for this behaviour will be discussed in the next section, where the responses in the North and East Mediterranean sub-regions will be analysed and compared.

\section{Interpreting the precipitation intensity response}

The precipitation generated by cyclones is influenced by both dynamical factors, e.g. the winds and vorticity of cyclones, and by the amount of moisture available in the atmosphere. Precipitation also feedbacks on cyclone dynamical intensity through diabatic heat release (Willison et al. 2013). Under climate change, the atmospheric moisture content is expected to increase (Finnis et al.
2007; Trenberth 2011), so that more precipitation might be generated by each extratropical cyclone. However, the cyclone dynamical intensity might not necessarily increase as this is also influenced by changes in the large scale atmospheric circulation and baroclinicity of the atmosphere.

The CMIP5 multi-model mean response in the $850 \mathrm{hPa}$ specific humidity and in the T42 vorticity intensity of cyclones at the same level are presented in Fig. 4b, c. In the multi-model mean, the specific humidity at $850 \mathrm{hPa}$ is projected to increase over the whole Mediterranean area, and in particular over the North Mediterranean (about $+20 \%$ compared to the historical values). On the other hand, the T42 $850 \mathrm{hPa}$ vorticity intensity of cyclones is projected to decrease over most of the Mediterranean area (Fig. 4c). In particular, a moderate reduction is found in the East Mediterranean, where the vorticity intensity of cyclones decreases by about $6 \%$ relative to the historical values. This reduction in cyclone dynamical intensity might oppose the increase in the atmospheric specific humidity in the precipitation intensity of cyclones.

This hypothesis has been tested by exploring the spread of the CMIP5 projections. Figure 5a, b present scatterplots of the area-averaged precipitation response due to changes in the precipitation intensity of cyclones $\delta \mu \cdot N^{20 C}$ in the North Mediterranean region against the responses in the $850 \mathrm{hPa}$ specific humidity and in the T42 vorticity intensity of cyclones area-averaged in the same region. The North Mediterranean region is defined by the box in Fig. 3b. Figure 5a shows that models with a larger increase in the atmospheric specific humidity tend to have a larger increase in the cyclone precipitation intensity $(\mathrm{r}=+0.55)$. Moreover, Fig. 5b shows that a positive correlation $(\mathrm{r}=+0.46)$ is also found with the future response in the
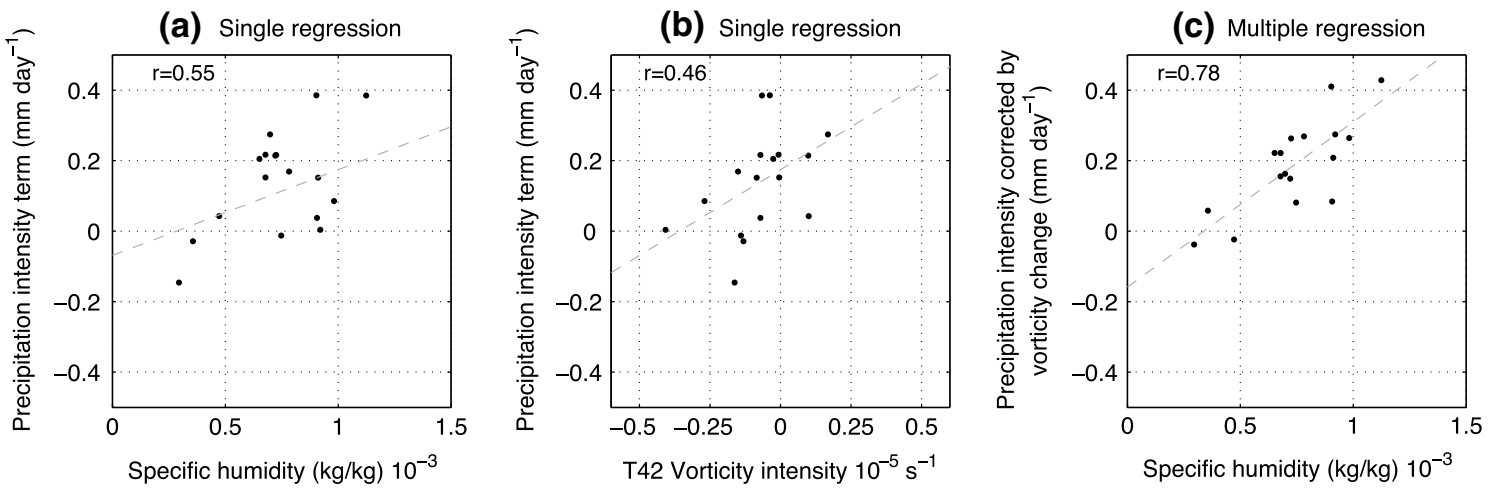

Fig. 5 Individual CMIP5 models precipitation response (RCP8. 5-HIST) in the North Mediterranean area due to changes in the average precipitation generated by cyclones versus a the response in the specific humidity at $850 \mathrm{hPa}$ and $\mathbf{b}$ the response in the dynamical intensity of cyclones (T42 vorticity). The regional values are obtained by area averaging over the North Mediterranean box presented in
Figs. $3 \mathrm{~b}$ and $4 \mathrm{~b}$, c. $\mathbf{c}$ is as $\mathbf{a}$, but the spread in the precipitation intensity response associated with the spread in the T42 vorticity intensity response has been linearly removed using a multiple linear regression. The multiple linear regression uses both the $850 \mathrm{hPa}$ specific humidity response and T42 cyclone vorticity intensity response as predictors 
Fig. 6 Same as Fig. 5a, b but for the East Mediterranean region (see East Mediterranean box shown in Figs. 3b, 4b, c) (a) Single regression

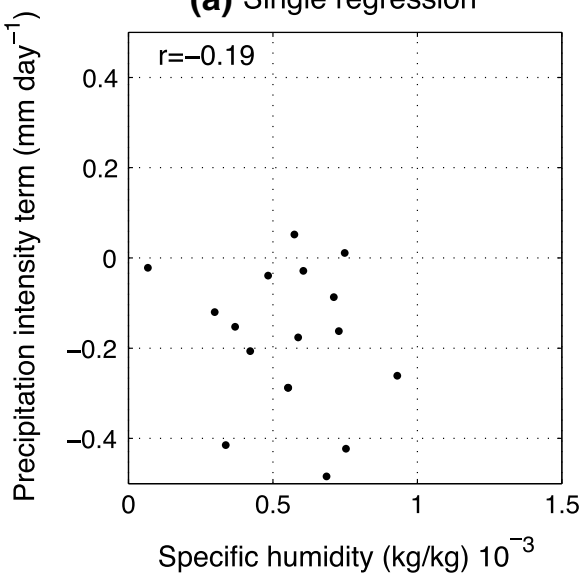

(b) Single regression

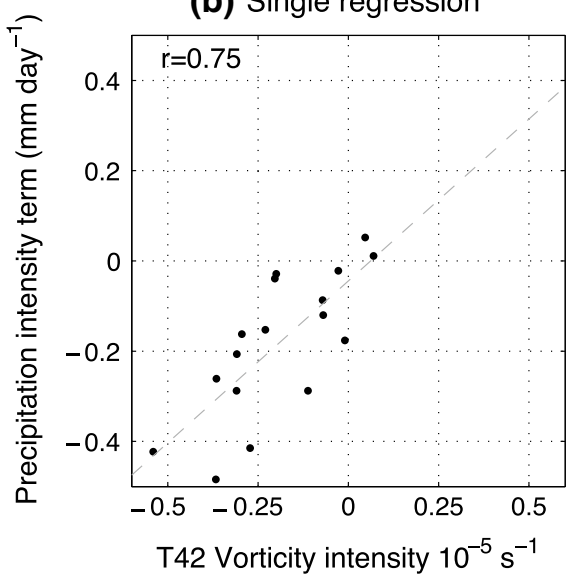

T42 vorticity intensity of cyclones. The two correlations are significant at the $10 \%$ level according to bootstrap resampling over the different models. Both factors seem to be important and we find that $68 \%$ of the inter-model spread in $\delta \mu \cdot N^{20 c}$ can be explained by a multiple linear regression which uses both the specific humidity and vorticity intensity responses as predictors (note the improved fit on specific humidity using the multiple linear regression in Fig. 5c).

The same analyses have been repeated for an East Mediterranean region (see box in Fig. 3b) and the related scatterplots are presented in Fig. 6a, b. In the inter-model spread, we find that the precipitation response due to changes in the precipitation intensity of cyclones is highly correlated $(\mathrm{r}=+0.75)$ with the response in the cyclone dynamical intensity (Fig. 6b). On the other hand, no significant correlation with the $850 \mathrm{hPa}$ specific humidity response is found in this region (Fig. 6a). This suggests that the projected reduction in the precipitation intensity of cyclones in the East Mediterranean is largely related to a dynamical weakening of the cyclones. A possible explanation is that East Mediterranean cyclone intensity is influenced by a local reduction in the atmospheric baroclinicity which is related to the weakening of the subtropical jet and the increase in atmospheric static stability [see, for example, Fig. 9 in Raible et al. (2010) and Fig. 9c in Zappa et al. (2013b)]. A more detailed analysis of this process is beyond the scope of this paper.

Overall, these results suggest that the changes in atmospheric moisture content and in the dynamical intensity of cyclones are both important to explain the future changes in the precipitation intensity of cyclones presented in Fig. 3b. The two factors are associated with opposite tendencies in the Mediterranean area, with the moisture content increase being dominant in the North Mediterranean region and the dynamical weakening of cyclones being more important in the East Mediterranean region.

\section{Conclusions}

This study has aimed at understanding the winter season (DJF) precipitation response to climate change in the Mediterranean area in terms of the changes in extratropical cyclones. This has been achieved by investigating an ensemble of CMIP5 coupled climate models simulations for present day (1976-2005) and future climate simulations (2082-2100) under the RCP8.5 scenario. The future precipitation response has been then decomposed between the contribution due to changes in the number of cyclones and that due to changes in the amount of precipitation generated by each cyclone.

The main findings of the study are the following:

- Up to $75 \%$ of the Mediterranean winter precipitation can be associated to Mediterranean cyclones in the CMIP5 climate models.

- The future reduction in the number of Mediterranean cyclones is the main driver of the overall reduction in precipitation in the Mediterranean basin under the RCP8.5 emission scenario. However, the future changes in the average precipitation generated by the individual cyclones are also locally important in the precipitation projections.

- In the North Mediterranean area, i.e. between $40^{\circ} \mathrm{N}$ and $45^{\circ} \mathrm{N}$, the reduction in the number of Mediterranean cyclones is compensated by an increase in the amount of precipitation generated by each cyclone. As a result, the winter mean precipitation response to climate change is projected to be small in the North Mediterranean in the multi-model mean.

- In the East Mediterranean area, i.e. Cyprus, Southern Turkey and the East Mediterranean coast, the average precipitation generated by the individual cyclones is projected to decrease, and this tends to amplify the decline in precipitation due to the reduction in the number of Mediterranean cyclones. 
- By investigating the inter-model spread in the CMIP5 projections, we find that the increase in cyclone precipitation intensity in the North Mediterranean area is primarily associated with an increase in the atmospheric moisture content. On the other hand, the reduction in precipitation intensity in the East Mediterranean area is largely associated with a dynamical weakening of the East Mediterranean cyclones.

These results confirm the importance of Mediterranean cyclones on Mediterranean precipitation which was previously suggested by Trigo et al. (2000) for the observed climate variability and by Lionello and Giorgi (2007) for a future climate projection. However, this study also provides new insights by considering how changes in the amount of precipitation generated by individual cyclones can affect the precipitation projections. This aspect was not considered in Lionello and Giorgi (2007) who attributed the small change in winter precipitation on the Northern part of the Mediterranean basin to a balance between reduced storminess in the Mediterranean and increased storminess in the East Atlantic and Central European regions. On the other hand, this study is consistent with both Lionello and Giorgi (2007) and Evans (2009) in identifying a weakening of the Mediterranean storm track as the main reason for the projected precipitation decline in the East Mediterranean region. Furthermore, the projected reduction in the average precipitation generated by the East Mediterranean cyclones is consistent with the reduction in the mean rain per rainy day found by Black (2009) in the Middle East in a regional climate model simulation.

It should be noted that the tendency for the average precipitation generated by East Mediterranean cyclones to decrease, does not imply that the frequency of extreme precipitation events will decrease too. Instead, a tendency to more intense precipitation events in the Mediterranean basin has been found by Goubanova and Li (2007) in climate model projections. Exploring the future changes in cyclone-associated extreme precipitation events (Pfahl and Wernli 2012) could help to provide physical insight in the response of extreme precipitation to climate change.

Future research should also focus at better understanding the physical drivers of future changes in the number and intensity of Mediterranean cyclones (Brayshaw et al. 2010). Furthermore, the Mediterranean Sea is a main source of moisture for the Mediterranean region, but it is still typically poorly represented in global climate models due the too coarse resolution of their ocean components (Gualdi et al. 2013). It would be therefore of interest to verify whether the conclusions of this study hold for high resolution coupled model simulations with a realistic representation of the Mediterranean Sea, such as those being produced for the Hydrological Cycle in Mediterranean
Experiment (HyMEX) project and for the Mediterranean region of the Coordinated Downscaling Experiment (MEDCordex) (Drobinski et al. 2014).

Acknowledgments The authors would like to thank K.I. Hodges for the technical assistance and the insightful discussions. We acknowledge the World Climate Research Programme's Working Group on Coupled Modelling, which is responsible for CMIP, and we thank the climate modelling groups (listed in Table 1 of this paper) for producing and making available their model output. For CMIP the US Department of Energy's Program for Climate Model Diagnosis and Intercomparison provides coordinating support and led development of software infrastructure in partnership with the Global Organisation for Earth System Science Portals. We also thank the ECMWF for the ERA-Interim data. This study is part of the Testing and Evaluating Model Simulations of European Storms (TEMPEST) project which is funded by NERC.

Open Access This article is distributed under the terms of the Creative Commons Attribution License which permits any use, distribution, and reproduction in any medium, provided the original author(s) and the source are credited.

\section{Appendix}

Radius of influence of Mediterranean cyclones

The radius of influence of Mediterranean cyclones is estimated by inspecting the radial distribution of precipitation around the cyclones. For computing this accurately, for each cyclone, the precipitation field is first spline interpolated to a grid in polar coordinates with the pole centered on the T42 vorticity maximum and resolution of $1^{\circ}$ in the angular coordinate and $0.5^{\circ}(\sim 50 \mathrm{~km})$ in the radial coordinate. The cyclone-associated precipitation field is then averaged along the angular coordinate and composited over all the Mediterranean cyclones, which are defined as those having maximum T42 vorticity intensity at $850 \mathrm{hPa}$ within the study area $\left(10^{\circ} \mathrm{W}-40^{\circ} \mathrm{E}, 30^{\circ} \mathrm{N}-45^{\circ} \mathrm{N}\right)$. For each CMIP5 model, the resulting precipitation intensity as a function of the radius is presented in Fig. $7 \mathrm{a}$ and its radial derivative presented in Fig. 7b.

For each CMIP5 model, the average precipitation intensity peaks within $4^{\circ}$ from the cyclone centre and it progressively decreases for increasing radial distance. This area of intense precipitation is the fingerprint of the cyclone activity. For high radial distances (e.g. $15^{\circ}$ ), the precipitation intensity levels off to a value of about $1.5 \mathrm{~mm} \mathrm{day}^{-1}$. This background precipitation can be interpreted as randomly sampled precipitation which is not necessarily associated with the cyclone activity itself.

The radius of influence can be evaluated as the radial distance from the cyclone centre where the average precipitation intensity approaches the background level. An inspection of the multi-model mean precipitation distribution 
(a) Average precipitation intensity

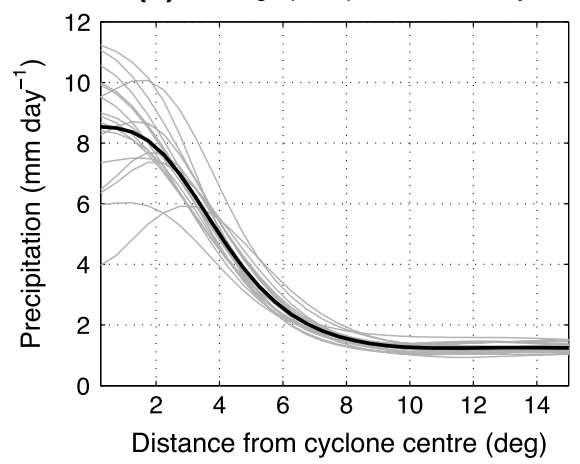

Fig. 7 a Precipitation intensity of the Mediterranean cyclones in the CMP5 models as a function of the radial distance from the cyclone T42 vorticity centre, and $\mathbf{b}$ radial derivative of the precipitation distribution shown in a. The grey lines refer to the individual CMIP5 mod-

(see Fig. 7a, b) suggests that a radius of influence of $10^{\circ}$ might be appropriate. Although the different CMIP5 models show very diverse behaviour in terms of both the precipitation intensity and shape close to the cyclone centre, smaller differences are found relative to the radius of influence. For example, if the radius is defined as the distance where the radial derivative of the precipitation intensity equals $-0.03 \mathrm{~mm} \mathrm{day}^{-1} \mathrm{deg}^{-1}$, the radius of influence of the different CMIP5 models lie, with two exceptions, between $9^{\circ}$ and $11^{\circ}$ (see Fig. 7b). For simplicity, a common radius of influence of $10^{\circ}$ is therefore adopted for all the CMIP5 models, but sensitivity tests using smaller radii of influence $\left(6^{\circ}\right.$ and $9^{\circ}$ ) have been also performed. In these tests, the amount of precipitation associated with cyclones decreases, but the relative importance of the contribution from changes in the number and in the precipitation intensity of cyclones (i.e. Fig. 3) remains largely unaltered (not shown). This gives us confidence that the choice of a relatively large radius $\left(10^{\circ}\right)$ does not affect the conclusions of the paper.

\section{References}

Arnell NW (2004) Climate change and global water resources: SRES emissions and socio-economic scenarios. Glob Environ Chang 14(1):31-52

Bengtsson L, Hodges KI, Roeckner E (2006) Storm tracks and climate change. J Clim 19:3518-3543

Black E (2009) The impact of climate change on daily precipitation statistics in Jordan and Israel. Atmos Sci Lett 10:192-200. doi:10.1002/asl.233

Black E, Brayshaw DJ, Rambeau CMC (2010) Past, present and future precipitation in the Middle East: insights from models and observations. Philos Trans R Soc A 368(1931):5173-5184. doi:1 0.1098/rsta.2010.0199

Brayshaw DJ, Hoskins B, Black E (2010) Some physical drivers of changes in the winter storm tracks over the North Atlantic (b) Radial derivative precipitation intensity

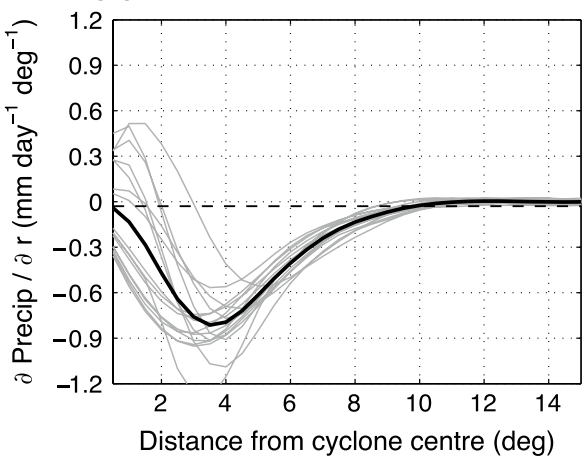

els and the black line gives the multi-model mean. In $\mathbf{b}$, the dashed line gives the threshold on the radial derivative of the precipitation intensity which is used to define the radius of influence of Mediterranean cyclones on precipitation

and Mediterranean during the Holocene. Philos Trans R Soc A 368(1931):5185-5223

Buzzi A, Malguzzi P, Trevisan A (1990) The statistical properties of the interaction of high-frequency eddies with mountains in a twolayer model. Tellus A 42:28-40

Catto JL, Pfahl S (2013) The importance of fronts for extreme precipitation. J Geophys Res Atmos 118:10791-10801. doi:10.100 2/jgrd.50852

Catto JL, Jakob C, Berry G, Nicholls N (2012) Relating global precipitation to atmospheric fronts. Geophys Res Lett 39(L10):805. doi:10.1029/2012GL051736

Collins M, Knutti R, Arblaster AM, Dufresne JL, Fichefet T, Friedlingstein P, Gao X, Gutowski WJ, Johns T, Krinner G, Shongwe M, Tebaldi C, Weaver AJ, Wehner M (2013) Long-term climate change: projections, commitments and irreversibility. In: Climate change 2013: the physical science basis. Contribution of working group I to the fifth assessment report of the intergovernmental panel on climate change. Cambridge University Press, Cambridge

Dee DP, Uppala SM, Simmons AJ, Berrisford P, Poli P, Kobayashi S, Andrae U, Balmaseda MA, Balsamo G, Bauer P (2011) The ERA-interim reanalysis: configuration and performance of the data assimilation system. Q J Roy Meteorol Soc 137:553-597

Diffenbaugh NS, Giorgi F (2012) Climate change hotspots in the CMIP5 global climate model ensemble. Clim Chang 114: 813-822

Drobinski P, Ducrocq V, Alpert P, Anagnostou E, Béranger K, Borga M, Braud I, Chanzy A, Davolio S, Delrieu G, Estournel C, Boubrahmi NF, Font J, Grubišić V, Gualdi S, Homar V, Ivančan-Picek B, Kottmeier C, Kotroni V, Lagouvardos K, Lionello P, Llasat MC, Ludwig W, Lutoff C, Mariotti A, Richard E, Romero R, Rotunno R, Roussot O, Ruin I, Somot S, Taupier-Letage I, Tintore J, Uijlenhoet R, Wernli H (2014) HyMeX: a 10-year multidisciplinary program on the mediterranean water cycle. Bull Am Meteorol Soc 95:1063-1082

Evans JP (2009) Global warming impact on the dominant precipitation processes in the Middle East. Theor Appl Climatol 99(3-4):389-402

Finnis J, Holland MM, Serreze M, Cassano J (2007) Response of Northern Hemisphere extratropical cyclone activity and associated precipitation to climate change, as represented by the Community Climate System Model. J Geophys Res 112:G04S42. doi: 10.1029/2006JG000286 
Geng Q, Sugi M (2003) Possible change of extratropical cyclone activity due to enhanced greenhouse gases and sulfate aerosolsstudy with a high-resolution AGCM. J Clim 16:2262-2274

Giorgi F (2006) Climate change hot-spots. Geophys Res Lett 33(L08):707

Goubanova K, Li L (2007) Extremes in temperature and precipitation around the Mediterranean basin in an ensemble of future climate scenario simulations. Glob Planet Chang 57:27-42

Gualdi S, Somot S, Li L, Artale V, Adani M, Bellucci A, Braun A, Calmanti S, Carillo A, Dell'Aquila A, Déqué M, Dubois C, Elizalde A, Harzallah A, Jacob D, L'Hévéder B, May W, Oddo P, Ruti P, Sanna A, Sannino G, Scoccimarro E, Sevault F, Navarra A (2013) The CIRCE simulations: regional climate change projections with realistic representation of the Mediterranean Sea. Bull Am Meteorol Soc 94:65-81

Hawcroft MK, Shaffrey LC, Hodges KI, Dacre HF (2012) How much Northern Hemisphere precipitation is associated with extratropical cyclones? Geophys Res Lett 39(L24):809

Hodges KI (1995) Feature tracking on the unit sphere. Mon Weather Rev 123:3458-3465

Hoskins BJ, Hodges KI (2002) New perspectives on the Northern Hemisphere winter storm tracks. J Atmos Sci 59:1041-1061

Jin F, Kitoh A, Alpert P (2010) Water cycle changes over the Mediterranean: a comparison study of a super-high-resolution global model with CMIP3. Philos Trans R Soc A 368:5137-5149

Jones PW (1999) First- and second-order conservative remapping schemes for grids in spherical coordinates. Mon Weather Rev 127:2204-2210

Kelley C, Ting M, Seager R, Kushnir Y (2012) Mediterranean precipitation climatology, seasonal cycle, and trend as simulated by CMIP5. Geophys Res Lett 39(L21):703

Lionello P, Giorgi F (2007) Winter precipitation and cyclones in the Mediterranean region: future climate scenarios in a regional simulation. Adv Geosci 12:153-158

Lionello P, Dalan F, Elvini E (2002) Cyclones in the Mediterranean region: the present and the doubled $\mathrm{CO}_{2}$ climate scenarios. Clim Res 22:147-159

Mariotti A, Zeng N, Yoon JH, Artale V (2008) Mediterranean water cycle changes: transition to drier 21st century conditions in observations and CMIP3 simulations. Environ Res Lett 3(044):001. doi:10.1088/1748-9326/3/4/044001

Nissen KM, Leckebusch GC, Pinto JG, Ulbrich U (2013) Mediterranean cyclones and windstorms in a changing climate. Reg Environ Chang. doi:10.1007/s10113-012-0400-8

Pfahl S, Wernli H (2012) Quantifying the relevance of cyclones for precipitation extremes. J Clim 25:6770-6780

Pinto J, Ulbrich U, Leckebusch G, Spangehl T, Reyers M, Zacharias S (2007) Changes in storm track and cyclone activity in three SRES ensemble experiments with the ECHAM5/MPI-OM1 GCM. Clim Dyn 29:195-210

Raible CC, Ziv B, Saaroni H, Wild M (2010) Winter synoptic-scale variability over the Mediterranean Basin under future climate conditions as simulated by the ECHAM5. Clim Dyn 35:473-488
Romem M, Ziv B, Saaroni H (2007) Scenarios in the development of Mediterranean cyclones. Adv Geosci 12:59-65

Schubert M, Perlwitz J, Blender R, Fraedrich K (1998) North Atlantic cyclones in $\mathrm{CO}_{2}$-induced warm climate simulations: frequency, intensity, and tracks. Clim Dyn 14:827-837

Seager R, Liu H, Henderson N, Simpson I, Kelley C, Shaw T, Kushnir Y, Ting M (2014) Causes of increasing aridification of the Mediterranean region in response to rising greenhouse gases. J Clim 27:4655-4676

Speranza A, Buzzi A, Trevisan A, Malguzzi P (1985) A theory of deep cyclogenesis in the lee of the Alps. Part I: modifications of baroclinic instability by localized topography. J Atmos Sci 42:1521-1535

Trenberth KE (2011) Changes in precipitation with climate change. Clim Res 47(1):123-138

Trigo IF, Davies TD, Bigg GR (1999) Objective climatology of cyclones in the Mediterranean region. J Clim 12:1685-1696

Trigo IF, Davies TD, Bigg GR (2000) Decline in Mediterranean rainfall caused by weakening of Mediterranean cyclones. Geophys Res Lett 27:2913-2916

Trigo IF, Bigg GR, Davies TD (2002) Climatology of cyclogenesis mechanisms in the Mediterranean. Mon Weather Rev 130:549-569

Ulbrich U, Leckebusch G, Pinto J (2009) Extra-tropical cyclones in the present and future climate: a review. Theor Appl Climatol 96:117-131

Ulbrich U, Leckebusch GC, Grieger J, Schuster M, Akperov M, Bardin MY, Feng Y, Gulev S, Inatsu M, Keay K, Kew SF, Liberato MLR, Lionello P, Mokhov II, Neu U, Pinto JG, Raible CC, Reale M, Rudeva I, Simmonds I, Tilinina ND, Trigo IF, Ulbrich S, Wang XL, Wernli H (2013) Are greenhouse gas signals of Northern Hemisphere winter extra-tropical cyclone activity dependent on the identification and tracking algorithm? Meteorol $\mathrm{Z}$ 22(1):61-68

Watterson I (2006) The intensity of precipitation during extratropical cyclones in global warming simulations: a link to cyclone intensity? Tellus A 58:82-97

Willison J, Robinson WA, Lackmann GM (2013) The importance of resolving mesoscale latent heating in the North Atlantic storm track. J Atmos Sci 70:2234-2250

Zappa G, Shaffrey LC, Hodges KI (2013a) The ability of CMIP5 models to simulate North Atlantic extratropical cyclones. J Clim 26:5379-5396

Zappa G, Shaffrey LC, Hodges KI, Sansom PG, Stephenson DB (2013b) A multimodel assessment of future projections of North Atlantic and European extratropical cyclones in the CMIP5 climate models. J Clim 26:5846-5862

Zappa G, Masato G, Shaffrey L, Woollings T, Hodges K (2014) Linking Northern Hemisphere blocking and storm track biases in the CMIP5 climate models. Geophys Res Lett 41:135-139. doi:10.1 002/2013GL058480 